\title{
Pitavastatin in cardiometabolic disease: therapeutic profile
}

\author{
Luis Masana*
}

\begin{abstract}
Statins effectively lower low-density lipoprotein-cholesterol (LDL-C) and reduce cardiovascular risk in people with dyslipidemia and cardiometabolic diseases such as Metabolic syndrome (MetS) or type 2 diabetes (T2D). In addition to elevated levels of LDL-C, people with these conditions often have other lipid-related risk factors, such as high levels of triglycerides, low levels of high-density lipoprotein-cholesterol (HDL-C), and a preponderance of highly atherogenic, small, dense low-density lipoprotein particles. The optimal management of dyslipidemia in people with MetS or T2D should therefore address each of these risk factors in addition to LDL-C. Although statins typically have similar effects on LDL-C levels, differences in chemical structure and pharmacokinetic profile can lead to variations in pleiotropic effects, adverse event profiles and drug-drug interactions. The choice of statin should therefore depend on the characteristics and needs of the individual patient. Compared with other statins, pitavastatin has distinct pharmacological features that translate into a broad range of actions on both apolipoprotein-B-containing and apolipoprotein-A-containing lipoproteins. Studies show that pitavastatin 1 to $4 \mathrm{mg}$ is well tolerated and significantly improves LDL-C and triglyceride levels to a similar or greater degree than comparable doses of atorvastatin, simvastatin or pravastatin, irrespective of diabetic status. Moreover, whereas most statins show inconsistent effects on HDL-C levels, pitavastatin-treated patients routinely experience clinically significant elevations in HDL-C that are maintained and even increased over the long term. In addition to increasing high-density lipoprotein quantity, pitavastatin appears to improve high-density lipoprotein function and to slow the progression of atherosclerotic plaques by modifying high-density lipoprotein-related inflammation and oxidation, both of which are common in patients with MetS and T2D. When choosing a statin, it is important to note that patients with MetS have an increased risk of developing T2D and that some statins can exacerbate this risk via adverse effects on glucose regulation. Unlike many statins, pitavastatin appears to have a neutral and even beneficial effect on glucose regulation, making it a useful treatment option in this high-risk group of patients. Together with pitavastatin's beneficial effects on the cardiometabolic lipid profile and its low potential for drug-drug interactions, this suggests that pitavastatin might be a useful lipid-lowering option for people with cardiometabolic disease.
\end{abstract}

\section{Introduction}

Numerous clinical trials have demonstrated that statins effectively lower low-density lipoprotein-cholesterol $(\mathrm{LDL}-\mathrm{C})$ and reduce cardiovascular $(\mathrm{CV})$ risk in people with dyslipidemia and Metabolic syndrome (MetS) or type 2 diabetes (T2D) [1,2]. A recent individual patient meta-analysis of 14 randomized clinical trials, for example, showed that a $1.0 \mathrm{mmol} / \mathrm{l}(38.6 \mathrm{mg} / \mathrm{dl})$ reduction in LDL-C was associated with a significant $21 \%$ proportional reduction in major vascular events in people with $\mathrm{T} 2 \mathrm{D}$

*Correspondence: luis.masana@urv.cat

Vascular Medicine and Metabolism Unit, University Hospital Sant Joan, IISPV, CIBERDEM, Rovira and Virgili University, Sant Llorenç, 21. 43201-Reus, Spain
$(0.79,0.72$ to $0.86 ; P<0.0001)$ and that the reduction was similar in people without T2D $(0.79,0.76$ to 0.82 ; $P<0.0001)$ [1]. Most international treatment guidelines recommend lowering LDL-C to $<2.6 \mathrm{mmol} / \mathrm{l}(100 \mathrm{mg} / \mathrm{dl})$ in patients with high $\mathrm{CV}$ risk and to $<1.8$ to $2.0 \mathrm{mmol} / \mathrm{l}$ (70 to $80 \mathrm{mg} / \mathrm{dl}$ ) in those at very high $\mathrm{CV}$ risk such as T2D with associated risk factors and established CV disease [3-7]. Despite these guidelines, the second Lipid Treatment Assessment Project (LTAP-2) showed that the proportion of patients who failed to achieve their recommended LDL-C target ranged from 16 to $53 \%$ across nine countries. Possible reasons for this failure include underdiagnosis, poor choice of first-line therapy, inadequate starting doses/failure to uptitrate or use 
additional therapy, and poor persistence with medications due to cost, adverse events and/or drug-drug interactions (DDIs) [8]. If LDL-C-target attainment rates are to be improved, these problems must be avoided. It is therefore important to tailor the choice of first-line lipidlowering agent according to a patient's individual clinical profile and therapeutic need.

Although LDL-C-lowering is important for the reduction of $\mathrm{CV}$ risk, studies have shown that the risk of $\mathrm{CV}$ events in patients that fully attain their recommended LDL-C-target is only reduced by about one-third [9], leaving substantial residual risk. In addition to elevated levels of LDL-C, people with MetS and T2D often have other lipid-related risk factors, such as high levels of triglycerides, low levels of high-density lipoproteincholesterol (HDL-C), and a preponderance of highly atherogenic, small, dense low-density lipoprotein particles [10-12]. The optimal management of dyslipidemia in people with these conditions should therefore address each of these risk factors in addition to LDL-C. However, further studies are required to fully understand the therapeutic benefits of the various lipid-lowering drugs for the reduction of residual risk and to better define nonlow-density lipoprotein treatment targets.

\section{Pitavastatin}

Pitavastatin is a relatively new member of the statin family. Pitavastatin was first introduced in Japan in 2003 for the treatment of primary hyperlipidemia or mixed dyslipidemia and has since been licensed for use in 13 countries worldwide, including the USA, Japan, China, Germany and Spain. Pitavastatin has recently been approved for use in 20 additional countries, including the UK, Australia, and France, and is pending approval in a further 12 countries. Compared with other statins, pitavastatin has a unique structure that contributes to a number of pharmacological benefits, including increased systemic bioavailability [13], a high level of oral absorption $[14,15]$ and potent effects on LDL-C and HDL-C [16-19]. This review will discuss the potential benefits for pitavastatin in the treatment of patients with MetS or T2D, focusing on its beneficial effects on the atherogenic lipid triad, its neutral effects on glycemic control and its reduced potential for DDIs.

\section{Pitavastatin reduces LDL-C in people with Metabolic syndrome or type $\mathbf{2}$ diabetes}

Numerous clinical trials have shown that pitavastatin is well tolerated and beneficially modifies the lipid profile with a similar or greater efficacy to equivalent doses of atorvastatin, rosuvastatin, simvastatin and pravastatin in a wide range of patient subgroups [20-30], including those with MetS or T2D [23,24,31]. For example, the 16-week, randomized head-to-head PATROL trial $(n=302)$ showed that pitavastatin $2 \mathrm{mg} /$ day reduced median LDL-C levels by $41 \%$ in patients with risk factors for coronary artery disease and elevated LDL-C levels $(\geq 3.63 \mathrm{mmol} / \mathrm{l} ; 140 \mathrm{mg} /$ dl), an effect that was noninferior to atorvastatin $10 \mathrm{mg} /$ day (44\%) and rosuvastatin $2.5 \mathrm{mg} /$ day (42\%) [30].

Similarly, a pivotal phase III study in 857 European patients with hypercholesterolemia or mixed dyslipidemia showed that 12-week treatment with pitavastatin $2 \mathrm{mg} /$ day reduced LDL-C by $39.0 \%$ compared with $35.0 \%$ with simvastatin $20 \mathrm{mg} /$ day $(P=0.014)$, whereas reductions with pitavastatin $4 \mathrm{mg} /$ day and simvastatin $40 \mathrm{mg} /$ day were $44.0 \%$ and $42.8 \%$, respectively $(P=\mathrm{NS})$ [21]. A second study in a similar population $(n=821)$ reported that 12-week treatment with pitavastatin $2 \mathrm{mg} /$ day reduced LDL-C by $37.9 \%$ compared with $37.8 \%$ with atorvastatin $10 \mathrm{mg} /$ day $(P=\mathrm{NS})(44.6 \%$ and $43.5 \%$, respectively, with pitavastatin $4 \mathrm{mg} /$ day and atorvastatin $20 \mathrm{mg} /$ day; $P=\mathrm{NS}$ ) [20]. Importantly, the majority of patients with hypercholesterolemia or mixed dyslipidemia achieved their recommended National Cholesterol Education Program ATP III [3] and European Atherosclerosis Society [5] LDL-C targets within 12 weeks of treatment $[20,21,32]$.

The Japanese long-term prospective post-marketing surveillance LIVALO Effectiveness and Safety (LIVES) Study $(n=20,279)$ [33] and the JAPAN-ACS study [27] a prospective, randomized, open-label study in patients with hypercholesterolemia and acute coronary syndrome (ACS) $(n=251)$ - showed that the LDL-C-lowering efficacy of pitavastatin was similar among patients with and without T2D $(-27.3 \%$ vs. $-29.7 \%$, respectively, in the LIVES study, and $-35.7 \%$ vs. $36.4 \%$ in the JAPAN-ACS study). Furthermore, a subgroup analysis of the 12-week, randomized, open-label CHIBA study $(n=53)$ showed that the percentage reduction from baseline in LDL-C was significantly greater with pitavastatin than with atorvastatin in patients with MetS $(45.8 \%$ vs. $39.1 \%$; $P=0.0495$ ) [23]. The CHIBA study was carried out in a relatively small population and results should therefore be treated with caution. However, the authors suggest that this difference may be due to the relationship between statin efficacy and obesity. Whereas the LDL-Clowering efficacy of atorvastatin was attenuated by increased waist circumference, body weight and BMI, pitavastatin's efficacy was unaffected by obesity-related parameters. Together these results suggest that pitavastatin might be useful for the reduction of LDL-C in people with MetS or T2D, many of whom are overweight or obese.

\section{Pitavastatin increases HDL-C levels in people with Metabolic syndrome or type $\mathbf{2}$ diabetes}

Patients with MetS or T2D typically have low levels of HDL-C in addition to high levels of LDL-C and 
triglycerides $[10,11]$. A subanalysis of the J-LIT study showed that a $2.6 \mathrm{mmol} / \mathrm{l}(10 \mathrm{mg} / \mathrm{dl})$ increase in HDL-C was associated with a $34.9 \%$ reduction in the risk of coronary events in patients with T2D [34]. Moreover, studies have shown that increasing HDL-C levels using statins can significantly reduce the progression of atherosclerosis and reduce $\mathrm{CV}$ and cerebrovascular risk in people with dyslipidemia irrespective of LDL-C levels [35-39].

Although most statins increase HDL-C levels to some extent, efficacy varies from statin to statin and effects are not always consistent between trials [39-41]. For example, the VOYAGER study - a meta-analysis of data from 32,258 high-risk individuals in 37 randomized clinical trials - showed dose-dependent increases in HDL-C ranging from 5.5 to $7.9 \%$ with rosuvastatin 5 to $40 \mathrm{mg}$ and from 4.2 to $5.3 \%$ with simvastatin 10 to $80 \mathrm{mg}$, whereas the increases observed with atorvastatin were inversely related to the dose, falling from $4.5 \%$ with $10 \mathrm{mg}$ to $2.3 \%$ with $80 \mathrm{mg}$ [40]. In contrast, pitavastatin-treated patients routinely experience clinically significant, reproducible elevations in HDL-C [22,42-44].

In the pivotal phase III studies, 12-week treatment with pitavastatin 2 to $4 \mathrm{mg}$ /day increased HDL-C levels by 4 to $6 \%$ - an effect that was similar among patients treated with simvastatin and atorvastatin $[20,21]$. However, the longer-term (52 week) Effects of Pitavastatin and Atorvastatin on HDL-cholesterol Levels in Patients with HyperLDL Cholesterolemia and Glucose Intolerance (PIAT) study showed that pitavastatin $2 \mathrm{mg} /$ day was associated with significant increases in HDL-C compared with atorvastatin $10 \mathrm{mg} /$ day $(8.2 \%$ vs. $2.9 \% ; P=0.031)$, an effect that was reflected by increasing levels of apolipoprotein A-1 $(5.1 \%$ with pitavastatin vs. $0.6 \%$ with atorvastatin; $P=0.019$ ) (Figure 1) [24].

In another long-term trial - the 70-month retrospective, single-center, observational CIRCLE study - HDL-C levels were increased by $13.4 \%$ with pitavastatin compared with only $7.0 \%$ with atorvastatin in patients with percutaneous coronary intervention $(n=743)(P=0.029)$ [44]. These data suggest that the high-density lipoprotein (HDL)-elevating effect of pitavastatin might increase over time. Consistent with this observation, an extension of the pivotal phase III studies showed that pitavastatinmediated elevations in HDL levels ultimately increased from $4 \%$ to $6 \%$ after 12 weeks to $14.3 \%$ after 60 weeks [22].

As for other statins [39], the degree of pitavastatin's HDL-C-elevating efficacy appears to be related to serum concentrations of HDL-C at baseline. For example, the PATROL study showed that neither pitavastatin nor atorvastatin had a significant effect on HDL-C levels in patients with hypercholesterolemia and high baseline levels of HDL-C $(\sim 1.55 \mathrm{mmol} / \mathrm{l} ; 60 \mathrm{mg} / \mathrm{dl})$ [30]. In

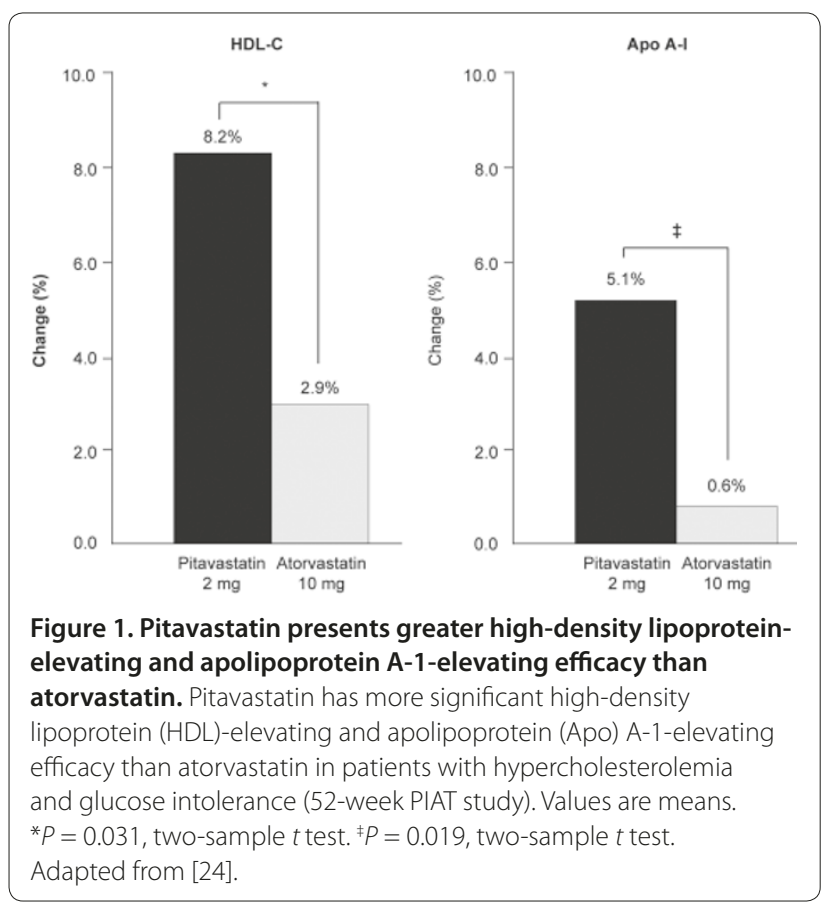

contrast, the KISHIMEN study in 178 Japanese subjects with hypercholesterolemia ( $58 \%$ with T2D) demonstrated significant pitavastatin-mediated elevations in HDL-C after 6 months ranging from $5.9 \%$ in the general cohort to $22.4 \%$ in patients with low baseline HDL-C $(<1 \mathrm{mmol} / \mathrm{l}$; $40 \mathrm{mg} / \mathrm{dl}$ ) [45]. Similarly, the increase in HDL-C achieved with pitavastatin in the CIRCLE study was $21.3 \%$ among patients with a low baseline HDL-C level $(\leq 1.17 \mathrm{mmol} / \mathrm{l}$; $45 \mathrm{mg} / \mathrm{dl}$ ) compared with $13.4 \%$ in the general population [44]. A subanalysis of the 2-year LIVES study showed that pitavastatin 1 to $4 \mathrm{mg}$ /day significantly increased HDL-C levels by $5.9 \%$ in all subjects $(n=631)$ and by 24.6\% $(P<0.0001)$ in those with a low baseline HDL-C $(<1 \mathrm{mmol} / \mathrm{l} ; 40 \mathrm{mg} / \mathrm{dl})(n=86)$ (Figure 2) [46]. Moreover, HDL-C levels rose by $15.8 \%$ after patients with persistently low levels of HDL-C despite previous statin treatment switched to pitavastatin [42]. This observation suggests that patients might benefit from pitavastatin therapy if HDL-C remains unacceptably low on other treatments.

\section{Pitavastatin-mediated high-density lipoprotein elevation has the potential to reduce residual risk via a number of mechanisms}

HDL particles are central to the reverse cholesterol transport pathway, a process in which excess cholesterol is removed from peripheral cells and transported to the liver for excretion into bile [11]. The suggestion has therefore been made that elevations in HDL-C might slow the formation of atherosclerotic plaques and may reduce the residual $\mathrm{CV}$ risk by increasing the rate of 


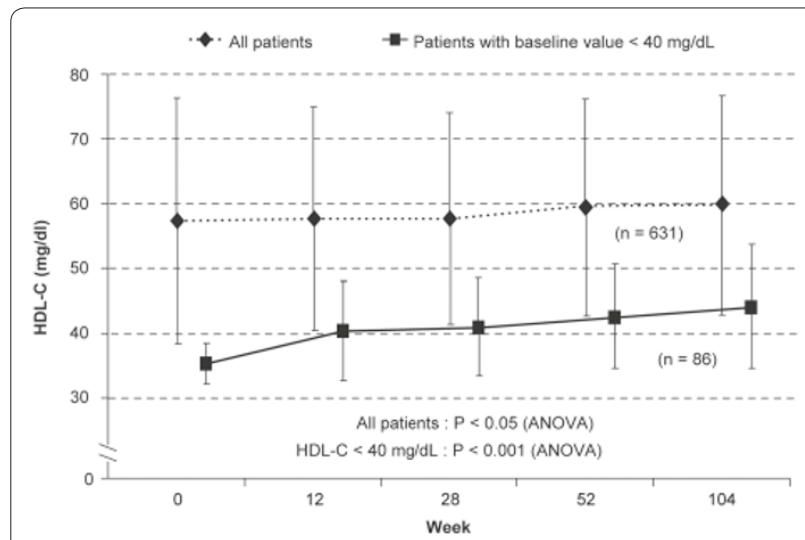

Figure 2. Pitavastatin presents high-density lipoproteincholesterol-elevating efficacy that increases with time. Pitavastatin has significant high-density lipoprotein-cholesterol (HDL-C)-elevating efficacy - especially in patients with low baseline $\mathrm{HDL}-\mathrm{C}$ - that continues to increase over time (LIVES HDL substudy). Values are mean \pm standard deviation. ANOVA, analysis of variance. Adapted from [46].

cholesterol efflux from cells. A post hoc analysis of intravascular ultrasonography data from four prospective randomized clinical trials $(n=1455)$ showed that statintreated patients with angiographic CHD experienced $\geq 5 \%$ reduction in the coronary atheroma volume when LDL-C levels were substantially decreased to $<2.21 \mathrm{mmol} / \mathrm{l}$ $(87.5 \mathrm{mg} / \mathrm{dl})$ and HDL-C levels were increased by $>7.5 \%$ [36]. However, a recent review of the literature suggests that, whilst the plaque volume change induced by a $1 \%$ reduction in LDL-C showed little difference using different statins (atorvastatin, pravastatin, pitavastatin, rosuvastatin, simvastatin), pitavastatin delivered the greatest reduction in plaque volume per $1 \%$ increase in HDL-C (Figure 3) [37]. Pitavastatin probably therefore beneficially modifies HDL function as well as quantity.

In addition to their role in reverse cholesterol transport, normal HDL particles can inhibit some of the atherogenic processes that occur in people with MetS and T2D, including increased oxidation [47-49], vascular inflammation [50,51], thrombosis [52], endothelial dysfunction [53], and reduced insulin sensitivity [54-56]. A 12-week, open-label multicenter study performed among 103 consecutive patients with hypercholesterolemia showed that patients with MetS $(n=69)$ had significantly higher mean levels of plasma high-sensitivity C-reactive protein and significantly lower mean levels of highmolecular-weight adiponectin than their counterparts without MetS $(n=34)$ [51]. In this study, a significant correlation was observed between baseline highmolecular-weight adiponectin levels and HDL-C values in patients with MetS $(r=0.318 ; P=0.01)$ but not in those without. Moreover, an effectiveness analysis including 62 patients with MetS and 32 patients without

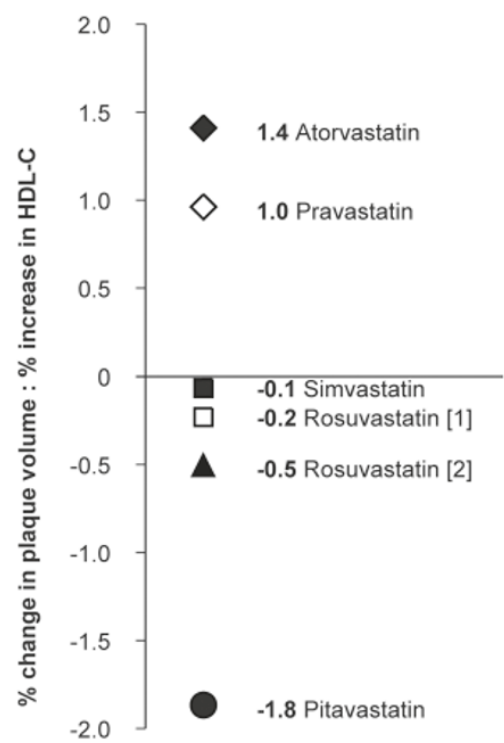

Figure 3. Pitavastatin induced greater plaque volume reduction by high-density lipoprotein cholesterol unit increase. Compared with other statins, pitavastatin is associated with the greatest reduction in plaque volume per $1 \%$ increase in high-density lipoprotein-cholesterol (HDL-C) (KISHIMEN study). Adapted from [37].

showed that the level of high-sensitivity C-reactive protein was significantly decreased in MetS patients during pitavastatin treatment, whereas high-molecularweight adiponectin levels did not change. When patients were grouped according to their percentage change in HDL-C, significantly greater pitavastatin-mediated increases in high-molecular-weight adiponectin were observed in patients with versus patients without HDL elevations $\geq 10 \%(P=0.009)$ (Figure 4). This observation suggests that pitavastatin might slow the progression of coronary atheromas by modifying HDL-related effects on inflammation and oxidation, both of which are common in people with MetS and T2D.

\section{Pitavastatin has a neutral effect on glucose control}

A number of clinical trials have highlighted a potential association between statin therapy and an increased risk of developing T2D [57-60]. For example, the Justification for the Use of Statins in Primary Prevention: An Intervention Trial Evaluating Rosuvastatin (JUPITER) study $(n=17,802)$ showed a significant $3.0 \%$ versus $2.4 \%$ increase in incident T2D among healthy adults treated with rosuvastatin $20 \mathrm{mg}$ /day versus placebo for 1.9 years $(P=0.01)$ [61]. Similarly, a meta-analysis of 13 statin trials including 91,140 patients without T2D showed that statin therapy (atorvastatin $10 \mathrm{mg}$, pravastatin $40 \mathrm{mg}$, simvastatin $40 \mathrm{mg}$ or rosuvastatin $20 \mathrm{mg}$ ) was associated with a $9 \%$ increased risk for T2D over 4 years (odds ratio $=1.09 ; 95 \%$ confidence interval $=1.02$ to 1.17 ) [58]. 


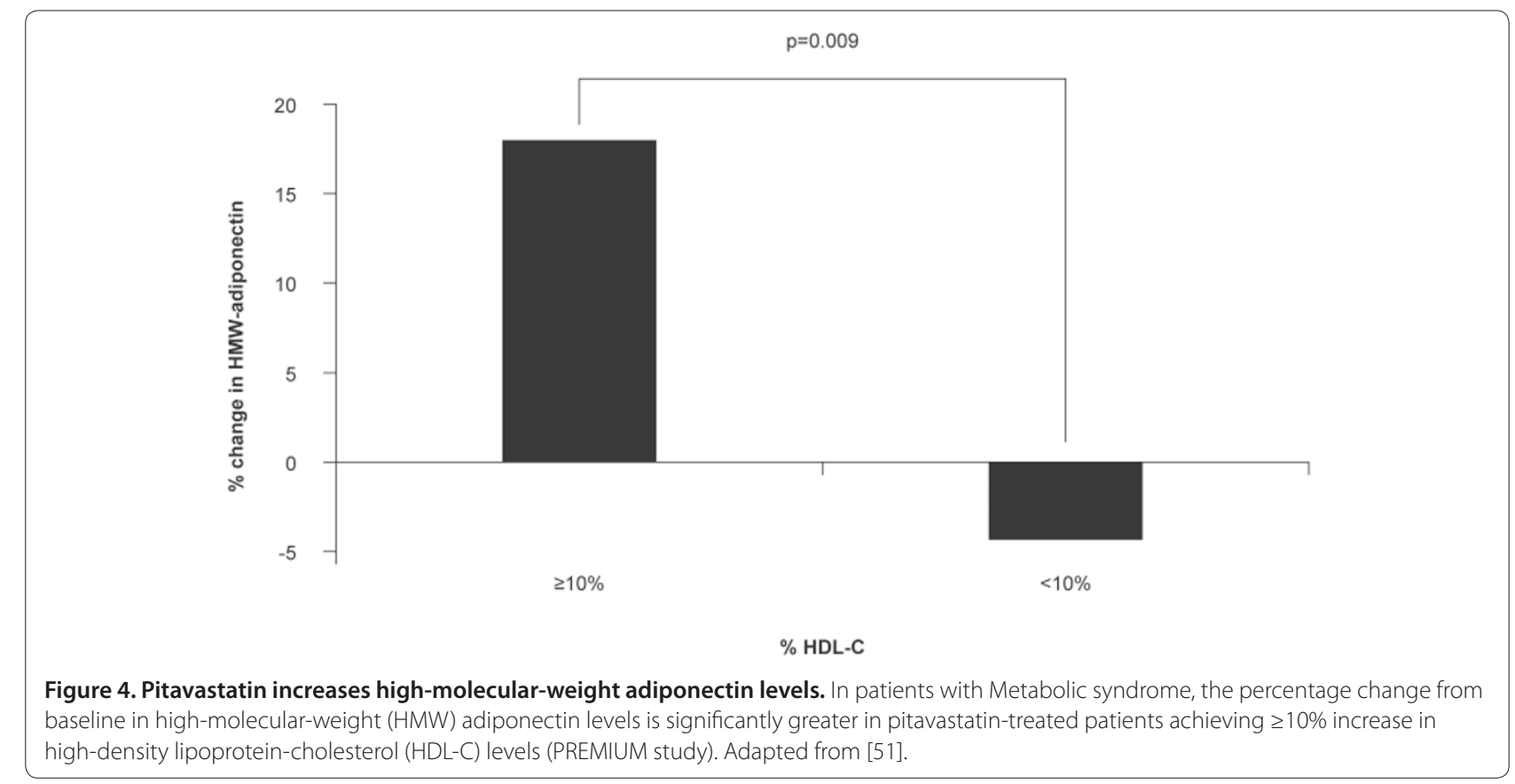

The mechanisms by which statins might cause this effect are unclear. A recent study carried out in 27 patients with well-controlled T2D suggests that the potential diabetogenic effects of simvastatin and rosuvastatin are not driven by a detrimental effect on insulin sensitivity, but rather by a deterioration of insulin secretion [62]. In this study, patients were randomly assigned to receive either rosuvastatin $20 \mathrm{mg} /$ day or simvastatin $20 \mathrm{mg} /$ day for 6 months followed by the other treatment for a further 6 months. Both strategies were associated with a similar 0.8 to $0.9 \%$ increase in hemoglobin A1c levels after 12 months $(P<0.001$ vs. baseline for both) and similar trends in fasting plasma glucose levels. No changes in insulin sensitivity were detected throughout the study, whereas HOMA $\beta$ levels were significantly decreased in both groups.

In contrast, the CAPITAIN study in 14 healthy male adults with well-defined MetS showed that 6-month treatment with the highest clinically available dose of pitavastatin ( $4 \mathrm{mg} /$ day) did not significantly change mean glucose-related or insulin-related parameters, including fasting plasma glucose, the Homeostasis Model Assessment index, insulin levels, insulin/glucose ratios, or hemoglobin A1c levels, and showed that glycemic parameters were generally improved [63]. Consistent with these results, a subanalysis of LIVES study data showed a significant $0.28 \%$ decrease in hemoglobin A1c levels $(P<0.001)$ among 308 patients with T2D after 2 years of pitavastatin treatment (Figure 5) [46]. These data suggest that whereas some statins are associated with adverse effects on glycemic control, pitavastatin has a neutral and

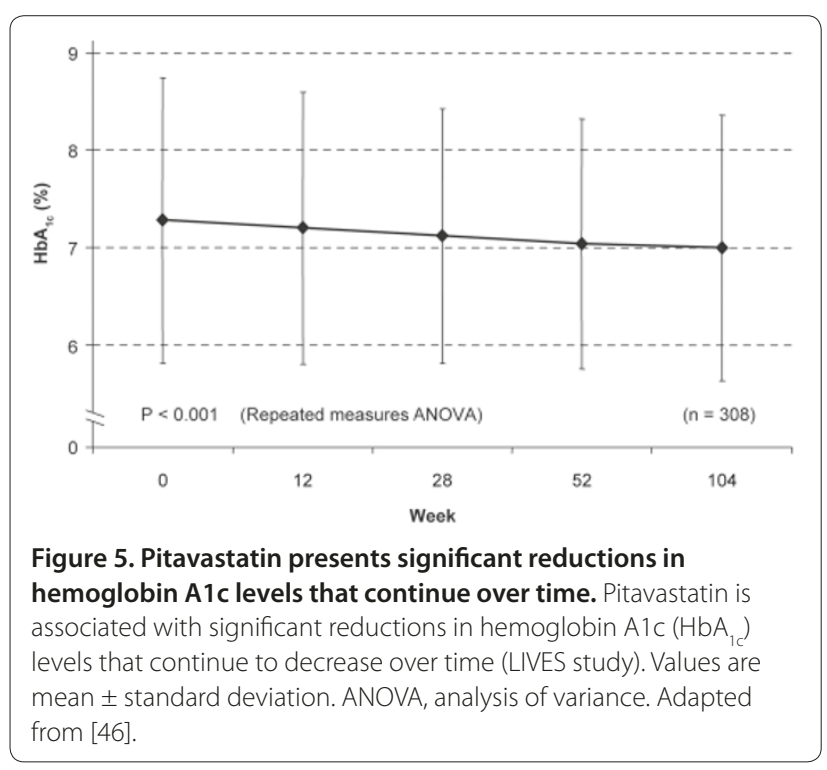

possibly beneficial effect that is likely to be especially useful in people with, or at risk of developing, T2D such as those with MetS. Definitive results on the impact of pitavastatin on the development of T2D are expected from the Japan Prevention Trial of Diabetes by Pitavastatin in Patients with Impaired Glucose Tolerance (J-PREDICT) study $(n \sim 1,240)$ in 2015 [64].

\section{Pitavastatin has a low potential for drug-drug interactions}

People with MetS or T2D usually require multiple therapies for a range of $\mathrm{CV}$ risk factors. A study of 
$>950,000$ patient records from two US databases showed that $83 \%$ of patients with dyslipidemia used a CYP3A4metabolized statin and that, of these, 25 to $30 \%$ also received a CYP3A4 inhibitor [65]. This suggests that patients treated with statins have a particularly high risk of developing DDIs, some of which may lead to drug discontinuations owing to adverse events. The best way to avoid this problem is to use a statin with a low potential for DDIs.

Whereas lovastatin, simvastatin and atorvastatin are metabolized mainly by CYP3A4 and fluvastatin and rosuvastatin are metabolized by $\mathrm{CYP} 2 \mathrm{C} 9$, pitavastatin's cyclopropyl group diverts the drug away from metabolism by CYP3A4 and allows only a small amount of clinically insignificant metabolism by CYP2C9. Moreover, studies in human hepatic microsomes have shown that, whereas the lactone metabolites of other statins are rapidly eliminated by CYP isoenzymes, both pitavastatin acid and lactone undergo limited metabolism [66]. It is not therefore surprising that the incidence of musclerelated adverse drug reactions identified during a post hoc analysis of the LIVES study was unaffected by the concomitant administration of pitavastatin with drugs known to inhibit a range of CYP isoenzymes [67]. These findings suggest that the pharmacokinetic data from interaction studies $[68,69]$ are predictive of clinical experience and that pitavastatin has a low potential for DDIs. To date, the use of pitavastatin is contraindicated only in patients treated with cyclosporin or lopinavir/ ritonavir combination therapy. Administration should be temporarily suspended in patients receiving erythromycin or fusidic acid, however, and the dosage should be limited to $2 \mathrm{mg}$ in people treated with rifampicin. As for other statins, pitavastatin should be used with caution in people treated with fibrates or niacin.

Overall, studies demonstrate that statins are well tolerated and have similar effects on LDL-C levels in people with and without MetS or T2D. Compared with other statins, however, pitavastatin has a unique structure that contributes to a number of pharmacological benefits. These include potent LDL-C-lowering efficacy, clinically significant, reproducible elevations in HDL-C, a neutral or beneficial effect on glycemic control and a reduced potential for DDIs. Pitavastatin is therefore likely to be a useful treatment option for people with MetS or T2D.

\section{Abbreviations}

$\mathrm{CV}$, cardiovascular; $\mathrm{DDI}$, drug-drug interaction; $\mathrm{HDL}$, high-density lipoprotein; HDL-C, high-density lipoprotein-cholesterol; LDL-C, low-density lipoproteincholesterol; MetS, Metabolic syndrome; T2D, type 2 diabetes.

\section{Competing interests}

LM is on the advisory boards of Amgen (GCAB), Sanofi, Danone, Esteve, and Recordati. LM has received lecture fees from MSD, Kowa, Danone, Esteve, Recordati, and Ferrer.

\section{Declaration}

This article has been published as part of Cardiovascular Diabetology Volume 12 Supplement 1, 2013: Statins in cardiometabolic disease: what makes pitavastatin different? The full contents of the supplement are available online at http://www.cardiab.com/supplements/12/S1. Publication of this supplement has been funded by Kowa Pharmaceutical Europe. Pitavastatin is a product marketed by the sponsor of the supplement. Articles are based on the proceedings of the World Congress for the Prevention of Diabetes. Authors received support with the preparation of their articles from GK Pharmacomm, an agency funded by the sponsor. All articles have undergone the journal's standard peer review process. The Supplement Editors declare that they have no competing interests.

\section{Published: 30 May 2013}

\section{References}

1. Kearney PM, Blackwell L, Collins R, Keech A, Simes J, Peto R, Armitage J, Baigent C: Efficacy of cholesterol-lowering therapy in 18,686 people with diabetes in 14 randomised trials of statins: a meta-analysis. Lancet 2008, 371:117-125.

2. Turner RC, Millns H, Neil HA, Stratton IM, Manley SE, Matthews DR, Holman RR: Risk factors for coronary artery disease in non-insulin dependent diabetes mellitus: United Kingdom Prospective Diabetes Study (UKPDS: 23). BMJ 1998, 316:823-828.

3. Third Report of the National Cholesterol Education Program (NCEP). Expert Panel on Detection, Evaluation, and Treatment of High Blood Cholesterol in Adults (Adult Treatment Panel III) final report. Circulation 2002, 106:3143-3421.

4. Grundy SM, Cleeman Jl, Merz CN, Brewer HB, Jr, Clark LT, Hunninghake DB, Pasternak RC, Smith SC, Jr, Stone NJ: Implications of recent clinical trials for the National Cholesterol Education Program Adult Treatment Panel III Guidelines. J Am Coll Cardiol 2004, 44:720-732.

5. Graham I, Atar D, Borch-Johnsen K, Boysen G, Burell G, Cifkova R, Dallongeville J, De BG, Ebrahim S, Gjelsvik B, Herrmann-Lingen C, Hoes A, Humphries S, Knapton M, Perk J, Priori SG, Pyorala K, Reiner Z, Ruilope L, Sans-Menendez S, Op Reimer WS, Weissberg P, Wood D, Yarnell J, Zamorano JL, Walma E, Fitzgerald T, Cooney MT, Dudina A, Vahanian A, et al.: European guidelines on cardiovascular disease prevention in clinical practice: full text. Fourth Joint Task Force of the European Society of Cardiology and other societies on cardiovascular disease prevention in clinical practice (constituted by representatives of nine societies and by invited experts). Eur J Cardiovasc Prev Rehabil 2007, 14(Suppl 2):S1-S113.

6. Genest J, McPherson R, Frohlich J, Anderson T, Campbell N, Carpentier A, Couture P, Dufour R, Fodor G, Francis GA, Grover S, Gupta M, Hegele RA, Lau DC, Leiter L, Lewis GF, Lonn E, Mancini GB, Ng D, Pearson GJ, Sniderman A, Stone JA, Ur E: 2009 Canadian Cardiovascular Society/Canadian guidelines for the diagnosis and treatment of dyslipidemia and prevention of cardiovascular disease in the adult - 2009 recommendations. Can J Cardiol 2009, 25:567-579.

7. Reiner Z, Catapano AL, De BG, Graham I, Taskinen MR, Wiklund O, Agewall S, Alegria E, Chapman MJ, Durrington P, Erdine S, Halcox J, Hobbs R, Kjekshus J, Filardi PP, Riccardi G, Storey RF, Wood D, Bax J, Vahanian A, Auricchio A, Baumgartner H, Ceconi C, Dean V, Deaton C, Fagard R, Filippatos G, Funck-Brentano C, Hasdai D, Hobbs R, et al.: ESC/EAS Guidelines for the management of dyslipidaemias: the Task Force for the management of dyslipidaemias of the European Society of Cardiology (ESC) and the European Atherosclerosis Society (EAS). Eur Heart J 2011, 32:1769-1818.

8. Masana L: Pitavastatin - from clinical trials to clinical practice. Atheroscler Suppl 2010, 11:15-22.

9. Baigent C, Keech A, Kearney PM, Blackwell L, Buck G, Pollicino C, Kirby A, Sourjina T, Peto R, Collins R, Simes R: Efficacy and safety of cholesterollowering treatment: prospective meta-analysis of data from 90,056 participants in 14 randomised trials of statins. Lancet 2005, 366:1267-1278.

10. Chapman MJ, Ginsberg HN, Amarenco P, Andreotti F, Boren J, Catapano AL, Descamps OS, Fisher E, Kovanen PT, Kuivenhoven JA, Lesnik P, Masana L, Nordestgaard BG, Ray KK, Reiner Z, Taskinen MR, Tokgozoglu L, TybjaergHansen A, Watts GF: Triglyceride-rich lipoproteins and high-density lipoprotein cholesterol in patients at high risk of cardiovascular disease: evidence and guidance for management. Eur Heart J 2011, 32:1345-1361.

11. Kontush A, Chapman MJ: Antiatherogenic small, dense HDL - guardian angel of the arterial wall? Nat Clin Pract Cardiovasc Med 2006, 3:144-153. 
12. Kontush A, Chapman MJ: Functionally defective high-density lipoprotein: a new therapeutic target at the crossroads of dyslipidemia, inflammation, and atherosclerosis. Pharmacol Rev 2006, 58:342-374.

13. Mukhtar RY, Reid J, Reckless JP: Pitavastatin. Int J Clin Pract 2005, 59:239-252

14. Neuvonen PJ, Niemi M, Backman JT: Drug interactions with lipid-lowering drugs: mechanisms and clinical relevance. Clin Pharmacol Ther 2006, 80:565-581.

15. Fujino H, Yamada I, Shimada S, Nagao T, Yoneda M: Metabolic fate of pitavastatin (NK-104), a new inhibitor of 3-hydroxy-3-methyl-glutaryl coenzyme A reductase. Effects on drug-metabolizing systems in rats and humans. Arzneimittelforschung 2002, 52:745-753.

16. Catapano AL. Pitavastatin - pharmacological profile from early phase studies. Atheroscler Supp/ 2010, 11:3-7.

17. Saito Y: Pitavastatin: an overview. Atheroscler Supp/ 2011, 12:272-276

18. Aoki T, Nishimura H, Nakagawa S, Kojima J, Suzuki H, Tamaki T, Wada Y, Yokoo N, Sato F, Kimata H, Kitahara M, Toyoda K, Sakashita M, Saito Y: Pharmacological profile of a novel synthetic inhibitor of 3-hydroxy-3methylglutaryl-coenzyme A reductase. Arzneimittelforschung 1997, 47:904-909

19. Morikawa S, Umetani M, Nakagawa S, Yamazaki H, Suganami H, Inoue K, Kitahara M, Hamakubo T, Kodama T, Saito Y: Relative induction of mRNA for HMG CoA reductase and LDL receptor by five different $\mathrm{HMG}-\mathrm{CoA}$ reductase inhibitors in cultured human cells. J Atheroscler Thromb 2000, 7:138-144.

20. Budinski D, Arneson V, Hounslow N, Gratsiansky N: Pitavastatin compared with atorvastatin in primary hypercholesterolemia or combined dyslipidemia. Clin Lipidol 2009, 4:291-302.

21. Ose L, Budinski D, Hounslow N, Arneson V. Comparison of pitavastatin with simvastatin in primary hypercholesterolaemia or combined dyslipidaemia. Curr Med Res Opin 2009, 25:2755-2764.

22. Ose L, Budinski D, Hounslow N, Arneson V: Long-term treatment with pitavastatin is effective and well tolerated by patients with primary hypercholesterolemia or combined dyslipidemia. Atherosclerosis 2010, 210:202-208.

23. Yokote K, Bujo H, Hanaoka H, Shinomiya M, Mikami K, Miyashita Y, Nishikawa T, Kodama T, Tada N, Saito Y: Multicenter collaborative randomized parallel group comparative study of pitavastatin and atorvastatin in Japanese hypercholesterolemic patients: collaborative study on hypercholesterolemia drug intervention and their benefits for atherosclerosis prevention (CHIBA study). Atherosclerosis 2008, 201:345-352.

24. Sasaki J, Ikeda Y, Kuribayashi T, Kajiwara K, Biro S, Yamamoto K, Ageta M, Kobori S, Saikawa T, Otonari T, Kono S: A 52-week, randomized, open-label, parallel-group comparison of the tolerability and effects of pitavastatin and atorvastatin on high-density lipoprotein cholesterol levels and glucose metabolism in Japanese patients with elevated levels of lowdensity lipoprotein cholesterol and glucose intolerance. Clin Ther 2008, 30:1089-1101.

25. Eriksson M, Budinski D, Hounslow N: Comparative efficacy of pitavastatin and simvastatin in high-risk patients: a randomized controlled trial. Adv Ther 2011, 28:811-823

26. Kimura K, Shimano H, Yokote K, Urashima M, Teramoto T: Effects of pitavastatin (LIVALO tablet) on the estimated glomerular filtration rate (eGFR) in hypercholesterolemic patients with chronic kidney disease. Sub-analysis of the LIVALO Effectiveness and Safety (LIVES) Study. J Atheroscler Thromb 2010, 17:601-609.

27. Hiro T, Kimura T, Morimoto T, Miyauchi K, Nakagawa Y, Yamagishi M, Ozaki Y, Kimura K, Saito S, Yamaguchi T, Daida H, Matsuzaki M; JAPAN-ACS Investigators: Diabetes mellitus is a major negative determinant of coronary plaque regression during statin therapy in patients with acute coronary syndrome - serial intravascular ultrasound observations from the Japan Assessment of Pitavastatin and Atorvastatin in Acute Coronary Syndrome Trial (the JAPAN-ACS Trial). Circ J 2010, 74:1165-1174.

28. Hiro T, Kimura T, Morimoto T, Miyauchi K, Nakagawa Y, Yamagishi M, Ozaki Y, Kimura K, Saito S, Yamaguchi T, Daida H, Matsuzaki M: Effect of intensive statin therapy on regression of coronary atherosclerosis in patients with acute coronary syndrome: a multicenter randomized trial evaluated by volumetric intravascular ultrasound using pitavastatin versus atorvastatin (JAPAN-ACS [Japan assessment of pitavastatin and atorvastatin in acute coronary syndrome] study). J Am Coll Cardiol 2009, 54:293-302.

29. Stender S, Hounslow N: Robust efficacy of pitavastatin and comparable safety to pravastatin. Atheroscler Supp/ 2009, 10:P770.
30. Saku K, Zhang B, Noda K: Randomized head-to-head comparison of pitavastatin, atorvastatin, and rosuvastatin for safety and efficacy (quantity and quality of LDL): the PATROL trial. Circ J 2011, 75:1493-1505.

31. Gumprecht J, Gosho M, Budinski D, Hounslow N: Comparative long-term efficacy and tolerability of pitavastatin $4 \mathrm{mg}$ and atorvastatin $20-40 \mathrm{mg}$ in patients with type 2 diabetes mellitus and combined (mixed) dyslipidaemia. Diabetes Obes Metab 2011, 13:1047-1055.

32. Teramoto T, Urashima M, Shimano H, Yokote K, Saito Y: A large-scale study on cardio-cerebrovascular events during pitavastatin (LIVALO tablet) therapy in Japanese patients with hypercholesterolemia LIVES 5-year extension study. Jpn Pharmacol Ther 2011, 39:789-803.

33. Kurihara Y, Douzono T, Kawakita K, Nagasaka Y. A large-scale, long-term prospective post-marketing surveillance of pitavastatin (Livalo) - Livalo effectiveness and safety study (LIVES). Jpn Pharmacol Ther 2008, 36:709-731.

34. Oikawa S, Kita T, Mabuchi H, Matsuzaki M, Matsuzawa Y, Nakaya N, Saito Y, Sasaki J, Shimamoto K, Itakura H: Risk of coronary events in Japanese patients with both hypercholesterolemia and type 2 diabetes mellitus on low-dose simvastatin therapy: implication from Japan Lipid Intervention Trial (J-LIT). Atherosclerosis 2007, 191:440-446

35. Teramoto T: Pitavastatin: clinical effects from the LIVES study. Atheroscler Supp/ 2011, 12:285-288.

36. Nicholls SJ, Tuzcu EM, Sipahi I, Grasso AW, Schoenhagen P, Hu T, Wolski K, Crowe T, Desai MY, Hazen SL, Kapadia SR, Nissen SE: Statins, high-density lipoprotein cholesterol, and regression of coronary atherosclerosis. JAMA 2007, 297:499-508

37. Kishida K, Funahashi T, Shimomura I: Importance of assessing the effect of statins on the function of high-density lipoproteins on coronary plaque. Cardiovasc Hematol Disord Drug Targets 2012, 12:28-34

38. Grover SA, Kaouache M, Joseph L, Barter P, Davignon J: Evaluating the incremental benefits of raising high-density lipoprotein cholesterol levels during lipid therapy after adjustment for the reductions in other blood lipid levels. Arch Intern Med 2009, 169:1775-1780.

39. Barter PJ, Brandrup-Wognsen G, Palmer MK, Nicholls SJ: Effect of statins on HDL-C: a complex process unrelated to changes in LDL-C: analysis of the VOYAGER Database. J Lipid Res 2010, 51:1546-1553.

40. Nicholls SJ, Brandrup-Wognsen G, Palmer M, Barter PJ: Meta-analysis of comparative efficacy of increasing dose of Atorvastatin versus Rosuvastatin versus Simvastatin on lowering levels of atherogenic lipids (from VOYAGER). Am J Cardiol 2010, 105:69-76.

41. Weng TC, Yang YH, Lin SJ, Tai SH: A systematic review and meta-analysis on the therapeutic equivalence of statins. J Clin Pharm Ther 2010, 35:139-151.

42. Teramoto $T$, Shimano $H$, Yokote $K$, Urashima M: Effects of pitavastatin (LIVALO Tablet) on high density lipoprotein cholesterol (HDL-C) in hypercholesterolemia. J Atheroscler Thromb 2009, 16:654-661.

43. Urashima M, Shimano H, Yokote K, Saito Y, Teramoto T: Association of highdensity lipoprotein cholesterol levels in pitavastatin treatment with risk of cardio-/cerebrovascular events in Japanese patients with dyslipidemia: analysis from the LIVES extension study [abstract]. J Am Coll Cardio/ 2011 57:E520.

44. Maruyama T, Takada M, Nishibori Y, Fujita K, Miki K, Masuda S, Horimatsu T, Hasuike T: Comparison of preventive effect on cardiovascular events with different statins. The CIRCLE study. Circ J 2011, 75:1951-1959.

45. Koshiyama H, Taniguchi A, Tanaka K, Kagimoto S, Fujioka Y, Hirata K, Nakamura Y, Iwakura A, Hara K, Yamamoto T, Kuroe A, Ohya M, Fujimoto S, Hamamoto Y, Honjo S, Ikeda H, Nabe K, Tsuda K, Inagaki N, Seino Y, Kume N: Effects of pitavastatin on lipid profiles and high-sensitivity CRP in Japanese subjects with hypercholesterolemia: Kansai Investigation of Statin for Hyperlipidemic Intervention in Metabolism and Endocrinology (KISHIMEN) investigatars. J Atheroscler Thromb 2008, 15:345-350.

46. Teramoto T, Shimano H, Yokote K, Urashima M: New evidence on pitavastatin: efficacy and safety in clinical studies. Expert Opin Pharmacother 2010, 11:817-828.

47. Navab M, Ananthramaiah GM, Reddy ST, Van Lenten BJ, Ansell BJ, Fonarow GC, Vahabzadeh K, Hama S, Hough G, Kamranpour N, Berliner JA, Lusis AJ, Fogelman AM: The oxidation hypothesis of atherogenesis: the role of oxidized phospholipids and HDL. J Lipid Res 2004, 45:993-1007.

48. Khera AV, Cuchel M, Llera-Moya M, Rodrigues A, Burke MF, Jafri K, French BC, Phillips JA, Mucksavage ML, Wilensky RL, Mohler ER, Rothblat GH, Rader DJ: Cholesterol efflux capacity, high-density lipoprotein function, and atherosclerosis. N Engl J Med 2011, 364:127-135.

49. Yamashita S, Tsubakio-Yamamoto K, Ohama T, Nakagawa-Toyama Y, Nishida 
M: Molecular mechanisms of HDL-cholesterol elevation by statins and its effects on HDL functions. J Atheroscler Thromb 2010, 17:436-451.

50. Barter PJ, Nicholls S, Rye KA, Anantharamaiah GM, Navab M, Fogelman AM: Antiinflammatory properties of HDL. Circ Res 2004, 95:764-772.

51. Matsubara T, Naruse K, Arakawa T, Nakao M, Yokoi K, Oguri M, Marui N, Amano T, Ichimiya S, Ohashi T, Imai K, Sakai S, Sugiyama S, Ishii H, Murohara T: Impact of pitavastatin on high-sensitivity C-reactive protein and adiponectin in hypercholesterolemic patients with the metabolic syndrome: the PREMIUM study. J Cardiol 2012, 60:389-394.

52. Mineo C, Deguchi H, Griffin JH, Shaul PW: Endothelial and antithrombotic actions of HDL. Circ Res 2006, 98:1352-1364

53. Tso C, Martinic G, Fan WH, Rogers C, Rye KA, Barter PJ: High-density lipoproteins enhance progenitor-mediated endothelium repair in mice. Arterioscler Thromb Vasc Biol 2006, 26:1 144-1149.

54. Drew BG, Duffy SJ, Formosa MF, Natoli AK, Henstridge DC, Penfold SA, Thomas WG, Mukhamedova N, de Court, Forbes JM, Yap FY, Kaye DM, van HG Febbraio MA, Kemp BE, Sviridov D, Steinberg GR, Kingwell BA: High-density lipoprotein modulates glucose metabolism in patients with type 2 diabetes mellitus. Circulation 2009, 119:2103-2111.

55. Fryirs MA, Barter PJ, Appavoo M, Tuch BE, Tabet F, Heather AK, Rye KA: Effects of high-density lipoproteins on pancreatic beta-cell insulin secretion. Arterioscler Thromb Vasc Biol 2010, 30:1642-1648.

56. von EA, Sibler RA: Possible contributions of lipoproteins and cholesterol to the pathogenesis of diabetes mellitus type 2. Curr Opin Lipidol 2011 22:26-32.

57. Preiss D, Seshasai SR, Welsh P, Murphy SA, Ho JE, Waters DD, DeMicco DA, Barter P, Cannon CP, Sabatine MS, Braunwald E, Kastelein JJ, de Lemos JA, Blazing MA, Pedersen TR, Tikkanen MJ, Sattar N, Ray KK: Risk of incident diabetes with intensive-dose compared with moderate-dose statin therapy: a meta-analysis. JAMA 2011, 305:2556-2564

58. Sattar N, Preiss D, Murray HM, Welsh P, Buckley BM, de Craen AJ, Seshasai SR, McMurray JJ, Freeman DJ, Jukema JW, Macfarlane PW, Packard CJ, Stott DJ, Westendorp RG, Shepherd J, Davis BR, Pressel SL, Marchioli R, Marfisi RM, Maggioni AP, Tavazzi L, Tognoni G, Kjekshus J, Pedersen TR, Cook TJ, Gotto AM, Clearfield MB, Downs JR, Nakamura H, Ohashi Y, et al: Statins and risk of incident diabetes: a collaborative meta-analysis of randomised statin trials. Lancet 2010, 375:735-742.

59. Sattar N, Taskinen MR: Statins are diabetogenic - myth or reality? Atheroscler Supp/ 2012, 13:1-10

60. Ray K: Statin diabetogenicity: guidance for clinicians. Cardiovascular Diabetology 2013, 12(Suppl 1):S3
61. Ridker PM, Danielson E, Fonseca FA, Genest J, Gotto AM, Jr, Kastelein JJ, Koenig W, Libby P, Lorenzatti AJ, MacFadyen JG, Nordestgaard BG, Shepherd $J$, Willerson JT, Glynn RJ: Rosuvastatin to prevent vascular events in men and women with elevated C-reactive protein. N Engl J Med 2008, 359:2195-2207.

62. Bellia A, Rizza S, Lombardo MF, Donadel G, Fabiano R, Andreadi K, Quon MJ, Sbraccia P, Federici M, Tesauro M, Cardillo C, Lauro D: Deterioration of glucose homeostasis in type 2 diabetic patients one year after beginning of statins therapy. Atherosclerosis 2012, 223:197-203.

63. Hounslow N, Robillard P, Suzuki M, Betting P, Giral P, Chapman MJ: Pitavastatin is without effect on glycaemic parameters in metabolic syndrome (CAPITAIN Study) [abstract]. Presented at World Congress of Diabetes, Madrid, 2012.

64. J-PREDICT Study Group: Japan Prevention Trial of Diabetes by Pitavastatin in Patients with Impaired Glucose Tolerance (J-PREDICT) [http://clinicaltrials.gov/ct2/show/NCT00301392]

65. Ming EE, Davidson MH, Gandhi SK, Marotti M, Miles CG, Ke X, McKenney JM: Concomitant use of statins and CYP3A4 inhibitors in administrative claims and electronic medical records databases. J Clin Lipidol 2008, 2:453-463.

66. Fujino H, Saito S, Tsunenari Y, Kojima J, Sakaeda T: Metabolic properties of the acid and lactone forms of HMG-CoA reductase inhibitors. Xenobiotica 2004, 34:961-971.

67. Teramoto T: Pitavastatin co-administration with CYP450 inhibitors does not increase the incidence of muscle-associated adverse drug reactions: 2-year data from 19,925 patients in the LIVES observational study [abstract]. In XVIInternational Symposium on Atherosclerosis - ISA2012; Sydney, 26 March 2012. [http://www.arinex.com.au/abstracts/isa2012/pdf/books/ Monday_Abstracts_ISA2012.pdf]

68. Morgan RE, Campbell SE, Suehira K, Sponseller CA, Yu CY, Medlock MM: Effects of steady-state lopinavir/ritonavir on the pharmacokinetics of pitavastatin in healthy adult volunteers. J Acquir Immune Defic Syndr 2012, 60:158-164.

69. Yu CY, Campbell SE, Zhu B, Knadler MP, Small DS, Sponseller CA, Hunt TL, Morgan RE: Effect of pitavastatin vs. rosuvastatin on international normalized ratio in healthy volunteers on steady-state warfarin. Curr Med Res Opin 2012, 28:187-194.

doi:10.1186/1475-2840-12-S1-S2

Cite this article as: Masana L: Pitavastatin in cardiometabolic disease: therapeutic profile. Cardiovascular Diabetology 2013, 12(Suppl 1):S2. 